\title{
Book Review: Gabi, a Girl in Pieces
}

\section{LORENA GERMÁN}

The Khabele Scool, Austin, TX
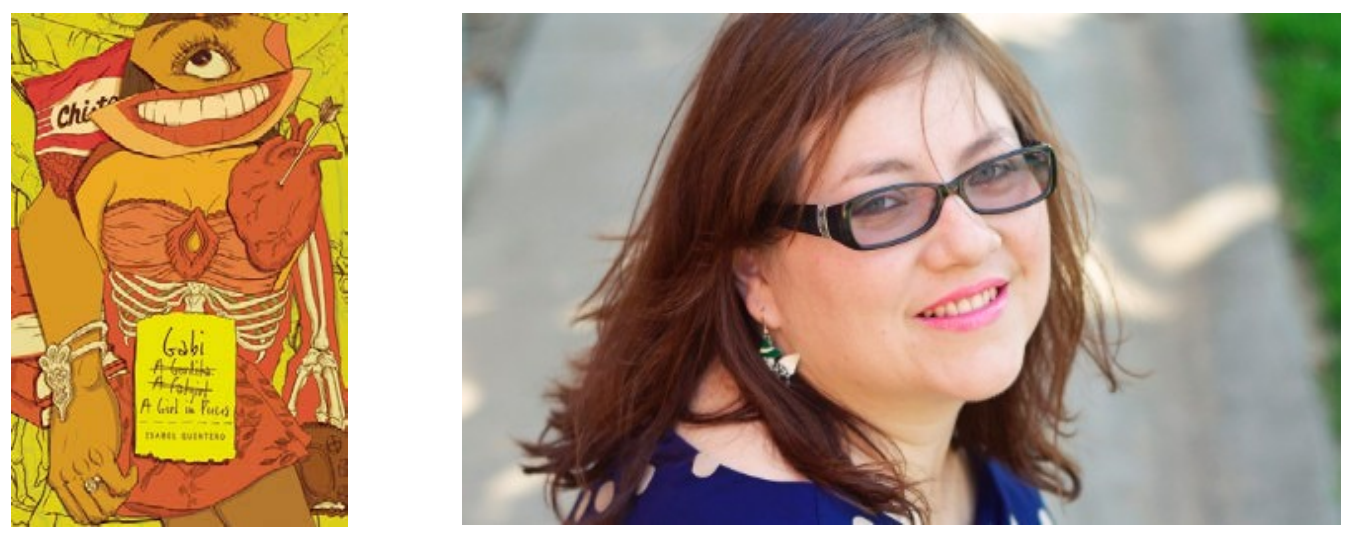

(photo of Isabel Quintero courtesy of Renna Marchman)

Quintero's protagonist, Gabi, is a high school senior swimming against the current of her last year and dealing with the all-too-real circumstances of first kisses, doing IT, college applications, homework, drugs, friends, and poetry. All the while trying to answer the question: what is a good Mexican girl? Her mother and aunt, the women with the two biggest influences in her life, are working diligently to pass on to her the culture of silence, conformity, and sacrifice that dominates Latina life. Gabi, on the other hand, is working diligently to question and reject it and thus find her own definition and way of being. What a journey! Quintero throws us abruptly into this life from the first page and doesn't let us take a break until the end. Her writing style is raw and honest and so real. Written in a diary style and infused with poems, unsent letters, and Spanish, Quintero is unapologetic about requiring the reader to join the ride and figure it out as you go along. It's like Gabi's life. And Quintero's strong position outside of the white gaze is refreshing.

The text forces us to explore issues around race and racism within and around Latin@ communities through Gabi’s light skin. She often faces questions about whether or not she's Mexican leading to people's surprise when she speaks Spanish. This is an important angle to her experience and poses 
a great opportunity for teachers to welcome these conversations around colorism and ancestry in Latin@ communities. Additionally, through her friendship and later romantic relationship with Martin, Gabi learns that bilingualism in writing is not only acceptable and possible, but powerful. Currently, urban public schools are over saturated by testing, standardized teaching, and canned curriculum. Thus, it is imperative for educators to welcome bilingualism as a celebration of the student and as an affirmation of their cultures. This leads to more academic engagement for students of color, whom otherwise often experience absence in their classroom content.

Gabi also learns about other ways of seeing God, gods, and life. She teaches us about practicing love and the impact that genuine care has on others. Gabi is strong and has clear convictions about womanhood and identity. Quintero delves into the intersection of Gabi's gender, race, religious beliefs, and cultural identity. She is a well-developed intelligent Latina main character in a sea lacking them. As a protagonist, Gabi shows us the complexity of being Latin@ while addressing certain stereotypes and rushing beyond them with authenticity.

As an educator, I couldn't help but read this and think of my students and their lives and that while I really believe that my assignments are essential to their being, they may be dealing with a lifechanging non-academic event. I need to account for that. Bringing in their voices, their experiences, their lives, their pain and joys is essential in providing young people with spaces to grow and examine those experiences. If my classroom doesn't allow for all my Gabis to analyze their lives and think critically about the world, then I am wrong.

As a Dominican-American, I couldn’t help but hear myself and my friends' journeys as I read. I heard my mother, my aunts, my friends, and my inner critic. This is an exemplary young adult novel that encourages deep and courageous conversations. In the classroom, it's a powerful opportunity to embrace issues around identity and self-acceptance.

LORENA GERMÁN is an English instructor at The Khabele School in Austin, TX. She can be reached at mrs.germanteacher@gmail.com and on Twitter @nenagerman. 